\title{
Nuestra América: Sus ideas De cómo América apoyó (¡debió ayudar!) a los EEUU y al mundo
}

- Horocio Cerutti Goldberg

Centro Coordinador y Difusor de Estudios Latinoamericanos

Divertimento ucrónico acerca de cómo hubiera sido la historia si no luera como es

(Una fraternal inviración de Ilugo Zernelman me llevio a participar en el Foro / Dehate organizado por el posdoctorado ('n pensamicento latinoamericano de la UCM sohre "¿Qué signilica y cómo se maniliesta en nuestro liempo la colonialidad del saber?", el dia 8 de octubre. El miércole's 3 lermini el lexto que aqui se incluye y en el cual juego con ideas de quiene's participamos en la mesa. Para los interesados en las posiciones de Edgardo Lander, Enrique Dussel y Aníhal Quijano, (f. Edgardo Lander (editor), La colonialidad del saber: eurocentrismo y ciencias sociales, perspeclivas latinoamericanas (Caracas, UNESCO / UCV, 20()(), 348 pág.s). lin (uanto a mis propias ide'as, (f. Rubén García Clarck, Luis Rangel y Kande Mutsaku, Filosofía, politica y utopia. En torno al pensamiento y a la obra de Horacio Cerutti Goldherg (México, UNAM, 2001, 342 págs.). Además, rétomo planteamientos de Carlos Lenkesdorf én alguno de sus estudios todavía inéditos sobre pensamiento tojolahal. Por supuesto, la responsabilidad es exclusivamente mia).

Año 2135. En una casita de los barrios recién restaurados de Bagdad -aquella ciudad que fue fundada en el siglo II de la hégira (s. VIII d.C.), llamada por su fundador, Al-Mansur (segundo califa abasí, 136-158 de la hégira / 754-775 d.C.) Madinat-as-Salam, la ciudad de la paz, con el fin de rememorar en la tierra el recuerdo del paraíso cósmico, el Dar as-Salam del Corán- pues

De cómo Américo apoyó (|debio oyudar!) a los USA y al mundo 
bien, en esa ciudad restaurada después de múltiples conflictos se recuperó un disquete que recoge datos fundamentales. El texto, muy valorado a inicios del tercer milenio de la era cristiana en aquellas regiones del globo, relata inverosímiles acontécimientos de la historia latinoamericana de la época y pasó del árabe al hebreo, luego al griego moderno, para vertirse al italiano, al finlandés y aparecer finalmente en mapuche y créole. Se hizo accesible en el adclantadísimo descendiente de los teléfonos celulares, que brinda directamente texto, imagen y sonido en la piel de las manos de los usuarios. Los fragmentos conservados se reproducen a continuación.

Cuando se vio por TV la segunda repetición -de una seric ininterrumpida y agobiante de reiteraciones de las mismas imágenes- de lo ocurrido el 11 de septiembre de $20(0)$ en Manhattan, la población latinoamericana se puso en marcha como si de una sola persona se tratase. Las principales cadenals de IV en todos los países de la región fueron ocupadas, enviados especiales fueron remilidos a los principales puntos del globo donde se gestaban los acontecimientos, los periódicos faltos de postura crítica o abiertamente amarillistas dejaron de comprarse y tuvieron que cerrar, las radios incrementaron hasta el límile de sus capacidades los programas de opinión y debate con especialistas en dilerentes facetas de la conflictiva realidad internacional. Pareciera que la población advirtió con fino olfato que era ya imposible seguir permitiendo que se siguiera construyendo la realidad por parte de los medios al libre arbitrio de los sectores hegemónicos. Era como si el nuevo orden informativo internacional, tan añorado en décalas anteriores, se hubiera puesto en marcha paradojicamente por iniciativa de los siempre pasivos espectadores.

La mayoría de los gobernantes entendió muy rápidamente el mensaje y comenzó a hacer valer la autoridad moral que todavía conservaba la región frente a su vecino del norte y, por supuesto, aquellos puntos de valor comercial y / o estralégicos desde donde podía reforzar su peso y presencia internacional. ()uienes no lo hicieron, luvieron que dejar sus puestos arrasiados por lo que parecía vigencia de una consigna coreada en innumerables marchas del (ono Sur en los años 60 y 7() del siglo $X X$ : con los dirigentes a la cabeza o con la cabeza de los dirigentes... Prefirieron conservar, sensalamente, sus cabezas...

Pareció como si las élites hegemónicas esluvieran, quizí por primera vez en la historia de la región, dispuestas a jugirselas con las poblaciones, con las grandes mayorías. Se hizo escurridizo el establecimiento del por (uić. Ouizii por un sano criterio de supervivencia. Dilicilmente por algo así como paltriotismo. I o (que se pudo constatar, en todo caso, es (jue la fuerza de la movilización generalizada de la población impuso sus reglas de juego. Auncue se les consideraha casi irrecuperables, a todos los tecnócratas se los envió a campamentos de rehabilitación y reeducación en la Antartida: tal era el afín de oponerse a la interprelación excluyentemente puniliva de la justicia. Se acabaron los presupuestos de guerra 
y las Fuerzas Armadas y de policia fueron reorganizadas como fuerzas de apoyo comunitario para la emergencia de la humanidad.

De manera sorprendente, entonces, los gohernantes de la region comenzaron a hacer recomendaciones sensatas a los gobernantes usamericanos. Pusieron sohre la mesa la necesidad de respetar un orden jurídico internacional en el cual la máxima de Benito Juárez. fucra la regla de oro: el respeto al derecho ajeno es la paz; insisticron en la imposihilidad de considerar la situacion como una guerra; se opusieron a que el Conscjo de Seguridad de la oNU dictara las pautas a seguir y exigieron la convocaloria a la Asamblea General; negaron cualquier tipo de apoyo a medidas de guerra que involucrarian — sin margen de error- a civiles inocentes: no aceeso a petróleo y otras materias primas estralcigicas, cierre de fronteras para produclos y visilantes usamericanos, control de visados actualizados, expulsion de todos los 'servicios' y luerzas militares o paramilitares de ese origen en la region cualquiera fuese el subterfugio como lucha contra el narco, asesoramientos técnicos, etc. ('omo contraparte, alentaron la repatriación de todos los connacionales que asi lo descaran con apoyos y subsidios para su renovada radicación en la region: el libre trínsito en toda la zona y procuraron garantizar los derechos laborales en estos países. (on la Union l:uropea impulsaron la ratilicación de lazos de cooperación basados en el mutuo respelo y condenaron inapelablemente a expulsión lisa y llana a acpuellas lirmas de ese origen que no acalaran las normas legales vigentes en estos paises

Is dilícil narrar - por la secuencialidad misma de la narración... lo que ocurria, porque los acontecimientos se yuxlaponian, se entremezclaban, se superponian unos a otros a una velocidad de cambio inaudito. I:I verrigo provenia. quizá y leído lodo a poseseriori, de una capacidad colectiva para sobreponerse al temor y para hacer valer la esperanza y la alirmación de la vida contra lodas las manipulaciones y chantajes habidos y por haber. ('omo si una oleada de lucidez alrapara masivamente, como si una epidemia de fraternidad incontenible se hubiera desatado de manera irreversible. Ante la luerza irrefrenable de esta energía positiva - ihumanista? - nadie se arredraba y los peores males de la humanidad iban cediendo como lrigiles artilicios. Todas las presuntas naturalizaciones manipuladas se visibilizaron casi de golpe y en un plumazo lueron historizadas a plenilud.

I a transformacion interna de la sociedad latinoamericana la hacia irreconocihle. I:I martiano aserto: no hay razas, se hizo realidad. Finalizada la discriminación sin fundamento biológico alguno, la democralización se institucionalizó sin una sola demora constitucional. Mandar obedeciendo y la luerza del NoSo. TROS se evidenciaron como los generadores de loda vida en comin respetable. la democracia directa en la calle, en la casa y en la cama se pracieci con pericia lal capaz. de rendir ante la evidencia: la inmensa cultura politica acumulada y potencial de la sociedad se hizo efectiva sin mís. Si hubo excesos fueron de

De cómo Américo opoyó (jdebió oyuderi!) a los USA y al mundo 
respeto, tolerancia, solidaridad, amor; sí, amor colectivo, a la especie y a la naturaleza. Como si un fuerte consenso se hubiera gestado en las entrañas de las experiencias comunes de la historia y surgiera con disposición total para aceptar pagar el preció, los altos costos, y correr los riesgos de la dignidad. Mujeres, niños, ancianos, pueblos indios, afroamericanos, homosexuales y lesbianas, campesinos, estudiantes, eclesiásticos, empleados, artesanos, expertos, técnicos, cienlíficos, académicos, intelectuales declararon un no rotundo a la guerra y apostaron por la paz. Se opusieron al apocalipsis y abricron espacio para el desenvolvimiento sin trabas de la tensión utópica.

Descubrieron en el ámbito donde lo extraordinario se manifiesta, el de la cotidianidad, que se podía lo imposible. Que tenían poder, capacidad de poderhacer en la medida en que intentaran transgredir límites aparentemente irrebasables. No sólo el futuro dejó de ser una tentación, si no que se hizo presente en plenitud. Con perplejidad todas y todos descubricron que el poder no viene de las máquinas, del know how o del better know, ni del clinero, la tecnología o de la fuerza, si no del asentimiento y cuando ese consentir se disipa, el poder se escurre de las manos de los dominadores como agua en una cesta. Tan simple como constatar que la pirámide se sostiene por la base...

En la intrincada resignificación en curso, la fuerza de la acción negadora latinoamericana hizo añicos ciertos mitos. La civilización moderna perdió su poder hegemónico en los imaginarios colectivos y dejó de ser comprendida (autocomprendida) como superior o más desarrollada. Acabó la ideologización eurocéntrica de las conciencias.

Como castillo de naipes se vino abajo la presunta exigencia moral que obligaba a desarrollar a los caracterizados e inventados como más primitivos, rudos. bárbaros, aunque no lo quisieran y mediante la sutil 'pedagogía' de pan y bombas... La pretendida y falaz unilinealidad del desarrollismo etapista dejó lugar a id-entidades múltiples y coexistentes, muchas veces gratamente complementarias. Dejó de justificarse toda violencia al quedar sin sustento los manidos argumentos 'humanitarios' de las guerras justas (muy sucias, por cierto) coloniales. Las víctimas se salieron del espacio ritual que les era asignado, recusando toda actitud sacrificial y exorcizando los holocaustos de los sedicentes 'salvadores". Por supuesto, ello conllevó la disolución de las atribuciones de 'culpas' a las víctimas y la no aceptación de sufrimientos impuestos para alcanzar 'madurez' coercitivamente. En fin, la pérdida de la inocencia autoatribuida de los centros dominantes hizo redescubrirse en toda su inocencia a las auténticas víctimas de la irracionalidad de un sistema de poder 'moderno' asfixiante de toda experiencia de la alteridad.

Una caravana, un humantour, como dijera algún periodista con sentido del humor, encabezada por Rigoberta Menchú y José Saramago se puso en marcha organizado por los zapatistas y la Confederación Ecuatoriana de Pucblos Indige- 
nas para llegar cuanto antes desde esta América hasta el lejano Afganistán. Todos los medios de transporte fucron utilizados, menos, por supuesto, los peligrosísimos aviones. Por aire, mar y ticrra avanzó esta caravana humanizadora hasta aquellas lierra ricas en petróleo y pobladas de empobrecidas poblaciones para llevar aliento y fraternidad. Las avanzadas globalifóbicas curopeas, alricanas y asiáticas llegaron antes en canoas, balsas, globos, camellos y biciclelas. El ambiente no se degradó. Por el contrario, se lueron sembrando plantas durante todo el viaje y ahora constituyen las huellas de una calzada por la (jue transilaron quienes se fueron percibiendo como ciudadanos del mundo, mientras avanzaban creciendo en número a cada paso. Todos los organismos internacionales humanilarios se sumaron a la caravana.

I a capacidad antropofaigica de esta América se mostró así en plenilud y cierlas preguntas pudieron reperculir a nivel internacional en lodos los loros, atrayendo la alención de las más lúcidas inteligencias de aquel liempo; aquellas inteligencias que tenemos todass y todos en nuestras vidas cotidianals, las cuales se nos fueron abriendo cada vez más y permitiendo la propia expresión. Menudearon las preguntas, como algunas de las (jue se enuncian a continuación:

- ¿Con qué molivos y objelivos se pudieron producir los repudial)les aconlecimientos de esal fechal?

- ¿Ouc antecedentes se podrian considerar"?

- ¿No es lrancamente absurdo e insultante aprohar un presupuesto caracterizado como de 'defensa' de 340 mil millones de dólares, cuando la $\Lambda\left({ }^{\circ} N\right.$ UR solicila 250 millones para subsanar algunas de las carencias más urgenles de aproximadamente 5 millones de personals que sólo ante la amenaza de guerra, no la guerra declarada, ya padecen sin cuento al límile de la sobrevivencia?

- ¿No se sabía desde antes, cuando cran aliados, de los excesos, lotalitarismos y brutalidades (especialmente contra las mujeres) de los ahora declarados como enemigos de lesal humanidad")

- ¿Quiéness son los oliciales y luncionarios de allo rango usamericanos somelidos a invesligacion y/o proceso por las lallas evidenles de su sistema de seguridad?

- ¿Cuáles son las prucbas y evidencias de las alribuidas culpabilidades?

- i.Cómo apoyar a los ciudadanos usamericanos que se alreven con allisimo mérito a cuestionar a su gobierno, por lo demás bastante ilegitimo descle los requisitos mínimos de una democracia representalival. Aquellos que valienlemente dejan su ignorancia a un lado y le exigen a sus gobernanles menos bravuconería y prepotencia y más responsabilidad. Los que recordaron lo fácil que es hablar de vigencia del estado de derecho cuando no han violado a lu hermana o matado a lus parientes. Insistieron: juslamenle en esos mo-

De cómo Américo apoyó (jdebió oyudar!) a los USA y al mundo 
mentos límites la salvación no consiste como en la películas del Far West - que ni fue far, ni rigurosamente west, ni mucho menos lierra de nadie...en desenfundar más rápido.

Etc., etc. Los interrogantes se ventilaron, se multiplicaron, la corporalidad latinoamericana se enquistó en su resistencia al consumismo, a la competencia indiscriminada, a los odios y terrores inventados. La pohlación resistió al EWS (End of the World Sex) para reivindicar un crotismo exultante de movimiento, ritmo, gozo y creatividad. Las sociedades del mundo, con sus respectivas y enriquecedoras culturas, pudieron incluir el tiempo como variable constructiva y no meramente dilatoria. El cambio se hizo tropel. Fue la primera vez en que la cartografía rutinaria se puso de cabeza y el norte fue el sur... Surearse fue la consigna de la hora, repetida por los jóvenes en todos los rincones del globo. I a historia siguió reencauzándose en una articulación inédita de justicia, paz, lihertad e igualdad, cuya proyección geométrica hace hoy (anio 21.3 .5 d.C.) factible la concreción de la esperanza. 